\title{
Bezobjawowa dławica naczynioskurczowa jako przyczyna nagłego zatrzymania krążenia
}

\section{Asymptomatic variant angina as the cause of sudden cardiac arrest}

\author{
Marek Elżbieciak, Katarzyna Mizia-Stec \\ I Katedra i Klinika Kardiologii Górnośląskiego Centrum Medycznego im. prof. Leszka Gieca \\ Śląski Uniwersytet Medyczny w Katowicach
}

\section{Streszczenie}

Dławica naczynioskurczowa (variant angina) jest formą niedokrwienia mięśnia sercowego wywołaną skurczem naczyń wieńcowych, przy czym obraz angiograficzny pozostaje prawidłowy lub prawie prawidłowy. Spazm tętnicy wieńcowej może doprowadzić do zawału serca i zatrzymania krążenia. W artykule przedstawiono historię 47-letniej pacjentki, która doznała zatrzymania krążenia w przebiegu spazmu prawej tętnicy wieńcowej, trudności diagnostyczne i trudne decyzje dotyczące dalszego leczenia.

Słowa kluczowe: dławica naczynioskurczowa, zatrzymanie krążenia, migotanie komór

Folia Cardiologica 2019; 14, 1: 67-70

\section{Wstęp}

Dławica naczynioskurczowa (variant angina) jest formą niedokrwienia mięśnia sercowego wywołaną skurczem naczyń wieńcowych, przy czym obraz angiograficzny pozostaje prawidłowy lub prawie prawidłowy. Przedłużony spazm tętnicy wieńcowej może doprowadzić do zawału serca i zatrzymania krążenia. Historia 47-letniej pacjentki z anoksemicznym uszkodzeniem mózgu, spastycznym niedowładem czterokończynowym przekazanej na oddział kardiologii 2 tygodnie po epizodzie nagłego zatrzymania krążenia (SCA, sudden cardiac arrest), najprawdopodobniej w mechanizmie migotania komór, jest przykładem istotności problemu, trudności diagnostycznych i niełatwych decyzji terapeutycznych.

\section{Opis przypadku}

Chora przebyła 20-minutową resuscytację krążeniowo-oddechową w warunkach domowych. Przez 3 dni przed przyjęciem do szpitala codziennie spożywała umiarkowane ilości alkoholu, nie skarżyła się na dolegliwości dławicowe, wiele lat paliła do 10 papierosów dziennie. W elektrokardiogramie (EKG) po resuscytacji obecny był częstoskurcz komorowy - pęczkowy nakładający się na przyspieszony rytm zatokowy (ryc. 1), badanie echokardiograficzne było prawidłowe. W badaniach laboratoryjnych zwracały uwagę wysokie stężenie D-dimerów (33 $000 \mathrm{ng} / \mathrm{ml}$ ), podwyższone wartości troponiny oznaczanej metodą wysokoczułą ([hsTn, high-sensitivity troponin] 0,082 ng/ml), frakcji sercowej kinazy kreatynowej ([CK-MB, creative kinase-myocardial bound] $92 \mathrm{ng} / \mathrm{ml}$ ) i glukozy (289 mg/dl), nie wykryto alkoholu, a stężenie potasu mieściło się w dolnej granicy normy $(3,8 \mathrm{mmol} / \mathrm{l})$. Wykonano angiografię tomografii komputerowej (CT, computed tomography) tętnic płucnych, wykluczając zatorowość płucną.

W trakcie badania EKG wykonywanego na oddziale przypadkowo uwidoczniono bezobjawowy epizod uniesienia odcinka ST w odprowadzeniach nad ścianą dolną, które wycofały się w ciągu 15 min (ryc. 2). Po epizodzie w UKG nie obserwowano odcinkowych zaburzeń kurczliwości, jednak zwracało uwagę hiperechogeniczne wsierdzie proksymalnych segmentów ściany dolnej (ryc. 3). Natomiast w koronarografii był obecny istotny spazm prawej tętnicy

Adres do korespondencji: dr n. med. Marek Elżbieciak, I Katedra i Klinika Kardiologii, Górnośląskie Centrum Medyczne im. prof. Leszka Gieca,

Śląski Uniwersytet Medyczny w Katowicach, ul. Ziołowa 47, 40-635 Katowice, e-mail: elzbie20@gmail.com 


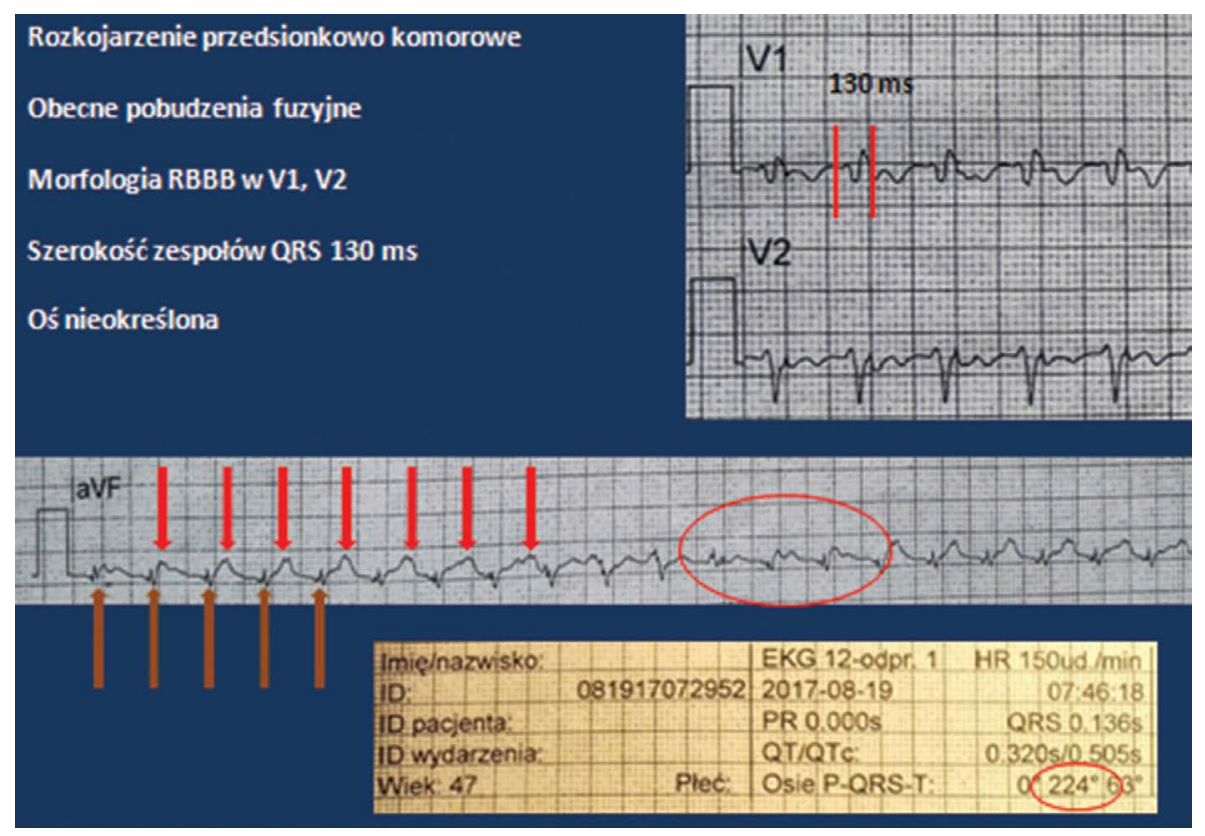

Rycina 1. Zapis elektrokardiograficzny (EKG) tuż po domowej resuscytacji krążeniowo-oddechowej - teletransmisja zespołu ratownictwa medycznego. Analiza poszczególnych odprowadzeń zapisu EKG: obecne rozkojarzenie przedsionkowo-komorowe, pobudzenia fuzyjne, w odprowadzeniach V1 i V2 zespoły QRS są poszerzone do 130 ms o morfologii jak w bloku prawej odnogi pęczka Hisa (RBBB, right bundle branch block), nieokreślona oś częstoskurczu świadcząca o pochodzeniu z przedniej wiązki lewej odnogi pęczka Hisa

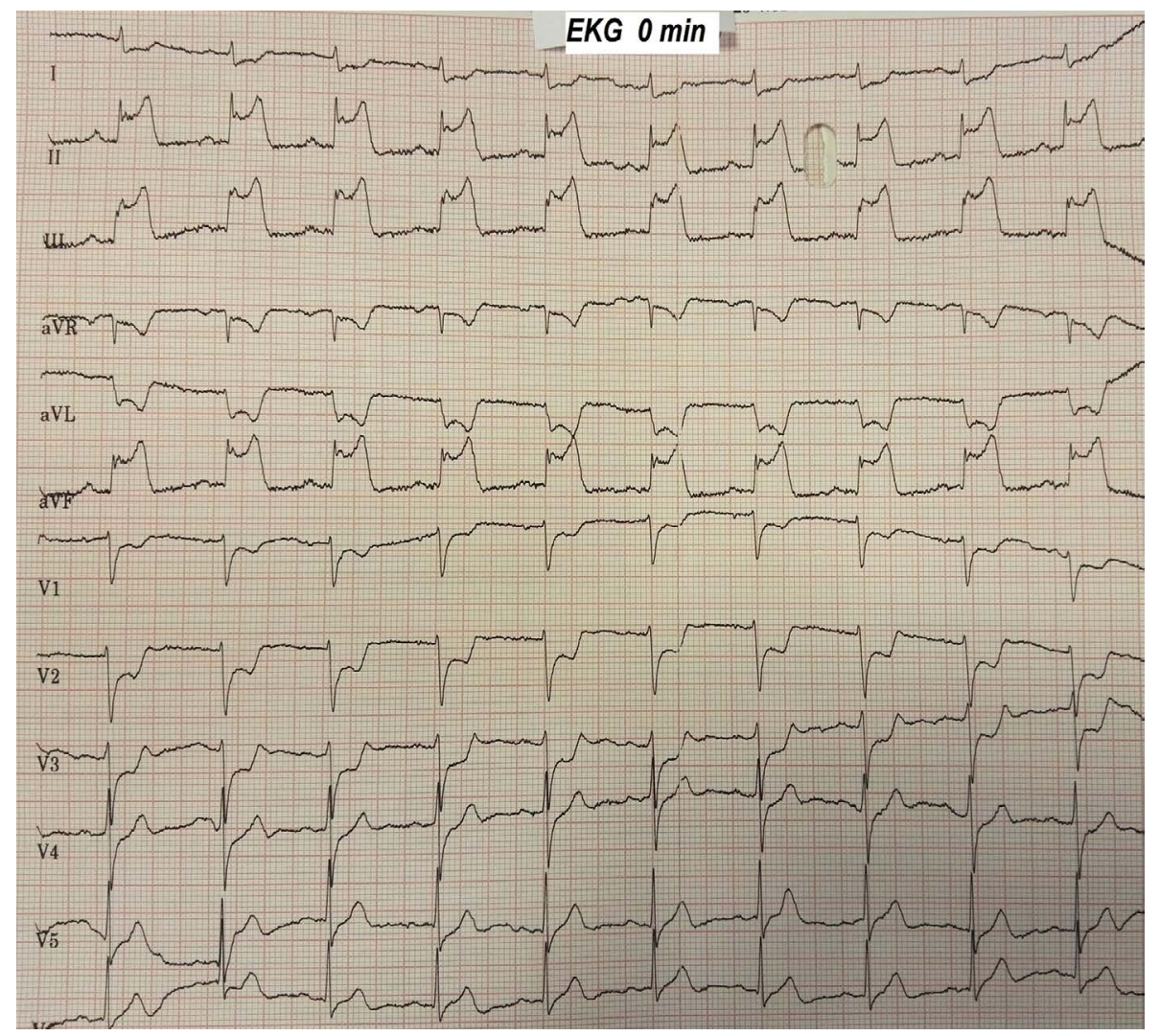

Rycina 2. Przesiewowe badanie elektrokardiograficzne (EKG) wykonane na oddziale - pacjentka nie odczuwała żadnych dolegliwości, widoczne uniesienia odcinka ST w odprowadzeniach nad ścianą dolną i obniżenia odcinka ST w odprowadzeniach przeciwnych 


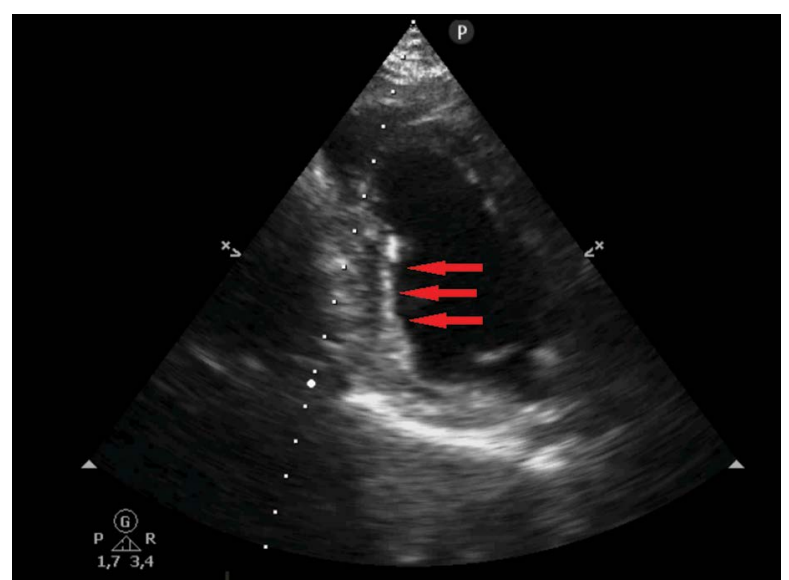

Rycina 3. Badanie echokardiograficzne wykonane po epizodzie niedokrwienia nieuwidoczniające zaburzeń kurczliwości odcinkowej; zwraca uwage hiperechogeniczne wsierdzie proksymalnych segmentów ściany dolnej - najpewniej blizna pozawałowa

wieńcowej. Po dowieńcowym podaniu nitrogliceryny ujawniono przyścienne zmiany miażdżycowe (ryc. 4).

Do leczenia włączono diltiazem w dawce 2 razy $90 \mathrm{mg}$ i monoazotan izosorbidu w dawce 2 razy $25 \mathrm{mg}$, suplementacje potasu i magnezu, kwas acetylosalicylowy oraz statynę. W kontrolnym badaniu EKG metodą Holtera nie obserwowano arytmii komorowej ani dynamiki odcinka ST. Pacjentkę przekazano na oddział rehabilitacji neurologicznej z zaleceniem zaprzestania palenia tytoniu i ponownej oceny kardiologicznej po wypisaniu w celu ewentualnej kwalifikacji do wszczepienia kardiowertera-defibrylatora (ICD, implantable cardioverter-defibrillator).

\section{Dyskusja}

Typowa postać dławcy naczynioskurczowej objawia się epizodami bólu w klatce piersiowej z przejściowymi uniesieniami ST w zapisach EKG. Dolegliwości występują w spoczynku, przeważnie w godzinach nocnych lub wczesnoporannych, wysiłek fizyczny nie indukuje niedokrwienia. Niebezpieczną postacią jest nieme niedokrwiene, które może się objawiać omdleniami spowodowanymi najczęściej wielokształtnym częstoskurczem komorowym, migotaniem komór czy blokiem przedsionkowo-komorowym.

Przyczynami spazmu tętnic wieńcowych są: niedostateczne wydzielanie tlenku azotu (NO, nitric oxide) przez uszkodzony śródbłonek naczyniowy, nadmierna ekspresja fosfolipazy C śródbłonka, zaburzenia równowagi w aktywacji układów przywspółczulnego i współczulnego, przewlekły resztkowy stan zapalny, niedobory magnezu, predyspozycje genetyczne, nadużywanie substancji zawierających epinefrynę lub/i kokainę, pochodzenie etniczne, hipotermia i zamieszkiwanie w chłodnym klimacie. W leczeniu wysoką skuteczność wykazują leki blokujace kanały wapniowe, długodziałające nitraty, suplementacja magnezu [1],

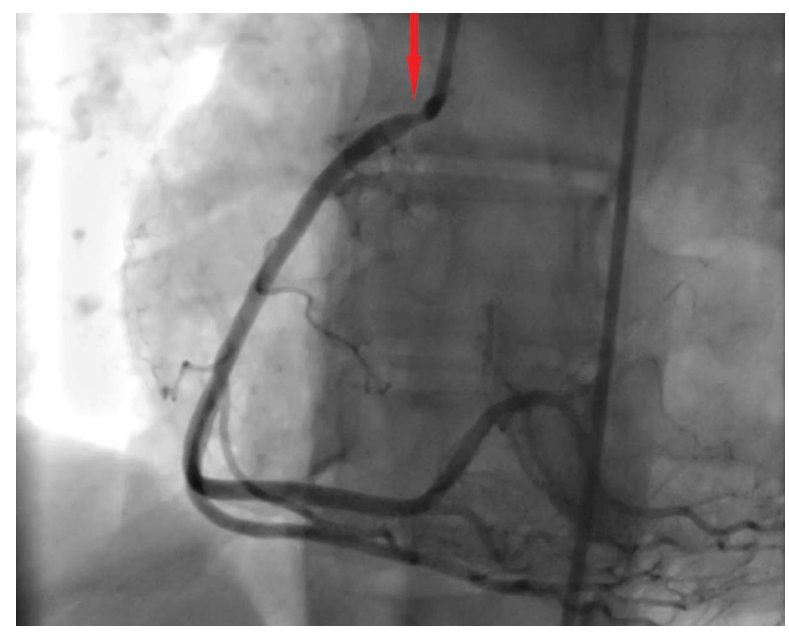

Rycina 4. Koronarografia - widoczny spazm proksymalnego odcinka prawej tętnicy wieńcowej

statyny [2], interwencje wieńcowe, takie jak angioplastyka wieńcowa [3], a nawet pomostowanie aortalno-wieńcowe [4]; u chorych po przebytym zatrzymaniu krążenia uznaną opcją terapeutyczną jest implantacja ICD [5].

Efekty leczenia farmakologicznego są dobre, a rokowanie jest pomyślne (przeżycie 5-letnie osiąga 98\% pacjentów, 92\% bez złożonego punktu końcowego definiowanego jako zgon z przyczyn sercowo-naczyniowych, zawał serca, hospitalizacja z powodu niestabilnej dławicy piersiowej lub niewydolności serca [poważnych zdarzeń sercowo-naczyniowych \{MACE, major adverse cardiac event\}]) [6]. U osób po przebytym zatrzymaniu krążenia 5-letnie przeżycie bez MACE jest znacznie gorsze i wynosi 72\% [7]. Istotna pozostaje ocena ryzyka nawrotu arytmii, między innymi. badanie elektrofizjologiczne, testy prowokacyjne acetylocholiną i ergonowiną. Eschalieri wsp. [8] zaproponowali prosty algorytm umożliwiający kwalifikację chorych po zatrzymaniu krążenia z powodu spazmu naczyń wieńcowych do implantacji ICD. Wyróżnili oni poddające się modyfikacji czynniki ryzyka, takie jak palenie tytoniu, hipotermia, nadużywanie leków, zaburzenia elektrolitowe, oraz czynniki niepodlegające modyfikacji: spazm „wielonaczyniowy”, dodatnie próby z zastosowaniem acetylocholiny i ergonowiny. Algorytm może pomóc w wyodrębnieniu grupy chorych, którzy odniosą korzyści z implantacji ICD [8].

Decyzja o odroczeniu wszczepienia ICD u opisanej wyżej pacjentki była zatem podyktowana obecnością czynników ryzyka podlegających modyfikacji, dobrą reakcją na leczenie farmakologiczne oraz tym, że spazm dotyczył pojedynczego naczynia. Chorą czekała długotrwała rehabilitacja neurologiczna.

\section{Konflikt interesów}

Autorzy deklarują brak konfliktu interesów. 


\section{Abstract}

Vasospastic angina is a form of myocardial ischaemia caused by coronary artery spasm, with normal or almost normal angiography. Spasm of the coronary artery can lead to myocardial infarction, ventricular fibrillation, and sudden cardiac death. This article presents the history of a 47 year-old female who suffered cardiac arrest in the course of right coronary artery spasm. We consider the diagnostic difficulties and decisions regarding further treatment.

Key words: variant angina, cardiac arrest, ventricular fibrillation

Folia Cardiologica 2019; 14, 1: 67-70

\section{Piśmiennictwo}

1. Teragawa H, Kato M, Yamagata $\mathrm{T}$, et al. The preventive effect of magnesium on coronary spasm in patients with vasospastic angina. Chest. 2000; 118(6): 1690-1695, indexed in Pubmed: 11115460.

2. Yasue $\mathrm{H}$, Mizuno $\mathrm{Y}$, Harada E, et al. SCAST (Statin and Coronary Artery Spasm Trial) Investigators. Effects of a 3-hydroxy-3-methylglutaryl coenzyme A reductase inhibitor, fluvastatin, on coronary spasm after withdrawal of calcium-channel blockers. J Am Coll Cardiol. 2008; 51(18): 17421748, doi: 10.1016/j.jacc.2007.12.049, indexed in Pubmed: 18452779.

3. Sueda S, Suzuki J, Watanabe K, et al. Comparative results of coronary intervention in patients with variant angina versus those with non-variant angina. Jpn Heart J. 2001; 42(6): 657-667, indexed in Pubmed: 11933916.

4. Ono T, Ohashi T, Asakura T, et al. Internal mammary revascularization in patients with variant angina and normal coronary arteries. Interact Cardiovasc Thorac Surg. 2005; 4(5): 426-428, doi: 10.1510/ icvts.2005.107128, indexed in Pubmed: 17670449.

5. Takagi Y, Yasuda S, Tsunoda R, et al. Japanese Coronary Spasm Association. Clinical characteristics and long-term prognosis of vasospastic angina patients who survived out-of-hospital cardiac arrest: multi- center registry study of the Japanese Coronary Spasm Association. Circ Arrhythm Electrophysiol. 2011; 4(3): 295-302, doi: 10.1161/ CIRCEP.110.959809, indexed in Pubmed: 21406685.

6. Takagi Y, Yasuda S, Takahashi J, et al. Japanese Coronary Spasm Association. Clinical implications of provocation tests for coronary artery spasm: safety, arrhythmic complications, and prognostic impact: multicentre registry study of the Japanese Coronary Spasm Association. Eur Heart J. 2013; 34(4): 258-267, doi: 10.1093/eurheartj/ehs199, indexed in Pubmed: 22782943.

7. Takagi Y, Yasuda S, Tsunoda R, et al. Japanese Coronary Spasm Association. Clinical characteristics and long-term prognosis of vasospastic angina patients who survived out-of-hospital cardiac arrest: multicenter registry study of the Japanese Coronary Spasm Association. Circ Arrhythm Electrophysiol. 2011; 4(3): 295-302, doi: 10.1161/ CIRCEP.110.959809, indexed in Pubmed: 21406685.

8. Eschalier R, Souteyrand G, Jean F, et al. Should an implanted defibrillator be considered in patients with vasospastic angina? Arch Cardiovasc Dis. 2014; 107(1): 42-47, doi: 10.1016/j.acvd.2013.10.006, indexed in Pubmed: 24373622. 